\title{
Quality and the curate's egg
}

\section{Felix Greaves, Ashish K Jha}

Department of Health Policy and Management, Harvard School of Public Health, Boston, Massachusetts, USA

\section{Correspondence to} Dr Felix Greaves,

Department of Health Policy and Management, Harvard School of Public Health, 677 Huntington Avenue, Boston, MA 02115-6018, USA; fgreaves@hsph.harvard.edu

Received 5 March 2014 Accepted 15 March 2014
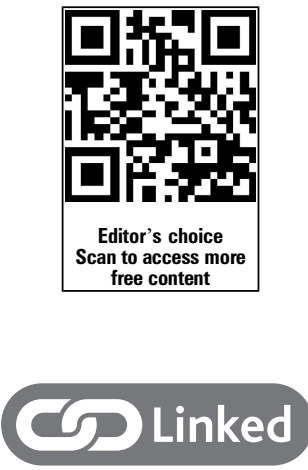

- http://dx.doi.org/10.1136/ bmjqs-2013-002707

\section{CrossMark}

To cite: Greaves F, Jha AK. BMJ Qual Saf 2014;23: 525-527.
A famous cartoon in the satirical magazine Punch from the 1890s shows a meek curate assuring his dinner host that his egg is not spoiled. "Parts of it are exceptional", he suggests. We, the knowing reader, appreciate the humour. An egg cannot be good in parts.

For those who think about quality, the question of whether care can be good in parts is a tricky one. That a hospital might deliver better care for one clinical service-top notch cardiac surgery, say, but below average stroke care-would not surprise anyone. But, the idea that quality itself, even within a given clinical domain, like cardiac surgery or stroke care, might be 'good in parts' has been recognised only recently. The US Institute of Medicine lays out six key dimensions of quality: effectiveness, safety, patientcenteredness, efficiency, timeliness and equity. ${ }^{1}$ In the UK, the National Health Service (NHS) highlights three domains of quality: clinical effectiveness, patient safety and the patient experience. ${ }^{2}$

As a result of this conceptual division, people have become interested in how these different parts relate to one another. Patient experience-traditionally the poor, subjective cousin in the quality family-sometimes struggles to defend its seat at the table.

Some have argued that measuring patient experience is a distraction. Take the patient dissatisfied by his doctor when he is denied antibiotics for a cold. This is bad for experience, but good clinical practice, and good for society. Many clinicians accept this disconnect between what they regard as appropriate care and what will make patients happy, seeing it as no more significant than a medication that tastes terrible. In acute care settings, hospital emergency rooms, for instance, clinicians may regret that patients often wait on stretchers that are uncomfortable, pillows are hard to find, and so on. But, when lives are being saved, comfort comes second.

Policymakers have not necessarily seen it this way and have pushed organisations to pay more attention to patient experience by using public reporting and pay-for-performance schemes that reward higher levels of patient satisfaction. In response, hospitals increasingly spend their hard-pressed money on cosmetic aspects of facilities and care, installing fountains in lobbies and having concert pianists serenade the guests. It is increasingly difficult to tell hospitals from the plush hotels they appear so keen to emulate $^{34}$ and critics wonder whether sky-high patient experience is just a marker of pandering to superficial expectations and inappropriate use of limited resources?

The push by policymakers has also led to the development of subjective patientcentred outcomes measures (PROMS), which some suggest may represent a new way to understand the effectiveness of care. In England, mandatory reporting of PROMS for a range of surgical procedures provides an opportunity not just to capture a patient's experience at the point of care, but also to measure their health experiences over a prolonged period.

A paper in this issue of the journal explores the relationship between experience and subjective measures of outcomes. Black et $a l^{5}$ examine the link between surgical patients' experience of care and their eventual outcomes in terms of safety and effectiveness. They find that patients who experience good care for hip replacements, knee replacements and groin hernia repairs tend to have better outcomes-in terms of subjective well-being-further down the line. The strength of the association is not terribly strong (with a correlation coefficient between 0.1 and 0.2), but it certainly seems to be there. They also found that those with better experience (1 SD above the average) were $30 \%$ less likely to have reported a complication.

This study adds to a body of literature that examines this relationship between patient experience and measures of both effectiveness and safety. A recent 
systematic review found that patient experience is usually positively associated with patient safety and clinical effectiveness across a range of diseases, populations and outcome measures. ${ }^{6}$ While a few studies suggest the opposite, ${ }^{7}$ most data indicate that providers with better patient experience scores also have better clinical outcomes. The presence of this association is reassuring because it suggests that there does not need to be a trade-off between patient experience and outcome when we provide care.

Why this relationship exists at all is a harder question to answer. The existence of distinct domains of quality reflects the fact that they seek to measure different phenomena, and one could have easily predicted that they would not be related at all. Organisations that focus on safety may not be efficient or patient centred. Yet, despite this possibility, many quality improvement experts have hoped that intensive efforts to improve one dimension will spill over into others.

Black and colleagues, explaining their findings, suggest that there might be a causal relationship between experience and effectiveness in either direction. Alternatively, the relationship may be confounded by a third factor. Perhaps patients, when they experience good care, are picking up on those intangible characteristics of a high performing organisation that lead to both great experience and great outcomes. What these characteristics are is a perennial question. It might be the soft but vital qualities of leadership and culture, or hard structural resources such as staffing levels and equipment. Finding the ingredients to this infuriatingly 'secret quality sauce' is an obvious goal for further research.

There is, however, another subtler question that also deserves our attention. If we take the view that each component of quality has its own intrinsic worth, how do we value the separate quality domains in comparison with one another? Is safety nonnegotiable? Should we pay most attention to effectiveness? Or should subjective experience be the deciding factor?

We need to be specific about the differential value that we wish to allocate to each component. This difficult task requires creating a hierarchy of outcomes and affects the degree to which each component should be incentivised. And this might not, in fact should not, be constant. It is context specific and should be decided by each service. It is entirely appropriate for a paediatric service to maximise safety, while palliative care might prioritise a good experience over other domains.

If priority setting in quality is to be attempted, the willingness of a health system to recognise and incorporate patient experience is critically important. While patient experience has previously been seen as a less valid entity, the clinical and policy discussion has clearly shifted in its favour. Manary et $a l^{8}$ suggest that patient experiences should be viewed as robust, distinctive indicators of healthcare quality. Berenson et $a l^{9}$ value the measurement of patient experience not as a mediator or proxy for other outcomes, but because it represents an important outcome in its own right.

Some even argue that patient experience should be less a component of quality, and more the overriding consideration through which to view the entire healthcare endeavour. Berwick reminds us that our true goal is not good healthcare, but good health. ${ }^{10}$ Good health is not measured just in terms of clinical endpoints such as years of life or cancer-free survival, but in terms of the ability to achieve goals that are important to people. Krumholz hints at an approach to quality in which measured subjective experience trumps other considerations. ${ }^{11}$ Although these views may sound like the idealised notions of 18th century utilitarian philosopher Jeremy Bentham, who suggested we should measure and maximise human happiness, ${ }^{12}$ they seem to have struck a chord. In Everyone Counts, the latest 4-year plan from NHS England, the verdict is clear: "The final arbiter of the outcome of any NHS interaction is the patient's experience". ${ }^{13}$

Quality is multifactorial by definition. Its measurement and improvement is consequentially complex. The parts appear to be all related, by mechanisms that we currently fail to understand. Quality need not run the risk of becoming a curate's egg - spoiled by poor performance in one of its many dimensions-if we align incentives that lead to good performance across the board. The evidence so far suggests that this is quite possible. At the same time, we need to face up to a difficult and context dependent decision and decide which parts of quality are the most important. Patient experience will surely have a role to play, but this will vary with specialty, condition, and even personal preference. To truly understand quality, we will have to look at both the sum and the function of its parts and understand it all within the context in which it was delivered.

Contributors Both authors contributed to the drafting of the manuscript.

Competing interests None.

Funding FG is supported by the Commonwealth Fund via a Harkness Fellowship.

Provenance and peer review Not commissioned; externally peer reviewed.

\section{REFERENCES}

1 Institute of Medicine. Crossing the quality chasm: a new health system for the 21st century. Washington, DC: National Academies Press, 2001.

2 Darzi A. High quality care for all: NHS next stage review final report. London: Department of Health, 2008. 
3 Goldman DP, Vaiana M, Romley JA. The emerging importance of patient amenities in hospital care. N Engl J Med 2010;363:2185-7.

4 Rosenthal E. Is This a Hospital or a Hotel? New York Times. 2013. [Internet] http://www.nytimes.com/2013/09/22/ sunday-review/is-this-a-hospital-or-a-hotel.html?_r $=0$ (accessed 3 Apr 2014).

5 Black N, Varaganum M, Hutchings A. Relationship between patient reported experience (PREMs) and patient reported outcomes (PROMs) in elective surgery. BMJ Qual Saf 2014;23: 534-42.

6 Doyle C, Lennox L, Bell D. A systematic review of evidence on the links between patient experience and clinical safety and effectiveness. BMJ Open 2013;3:e01570.

7 Fenton JJ, Jerant AF, Bertakis KD, et al. The cost of satisfaction: a national study of patient satisfaction, health care utilization, expenditures, and mortality. Arch Int Med 2012;172:405-11.
8 Manary MP, Boulding W, Staelin R, et al. The patient experience and health outcomes. $N$ Engl J Med 2012;368:201-3.

9 Berenson RA, Pronovost PJ, Krumholz HM. Measure patient experience with care and patient-reported outcomes as ends in themselves [Internet]. http://thehealthcareblog.com/blog/2013/05/ 26/4-measure-patient-experience-with-care-and-patient-reportedoutcomes-as-ends-in-themselves/ (accessed 3 Apr 2014).

10 Berwick DM. Institute for Healthcare Improvement 25th National Forum Keynote Address [Internet]. Youtube. 2013. http://www.youtube.com/watch?v=r5Tbikk44jY (accessed 3 Apr 2014).

11 Krumholz HM. Patient-centered medicine: the next phase in health care. Circ Cardiovasc Qual Outcomes 2011;4:374-5.

12 Bentham J. An introduction to the principles of morals and legislation. London: W. Pickering, 1823.

13 NHS Commissioning Board. Everyone counts: planning for patients 2013/14. London: Department of Health, 2013. 